Proceeding Paper

\title{
Pakistan's Energy Demand Forecasting for Various Sector through Long Range Alternative Planning System ${ }^{\dagger}$
}

\author{
Muhammad Mahboob ${ }^{1, *(\mathbb{D})}$, Muzaffar Ali ${ }^{1} \mathbb{D}$, Tanzeel ur Rashid ${ }^{1}$ and Rabia Hassan $^{2} \mathbb{D}$ \\ 1 Department of Mechanical Engineering, UET, Taxila 47080, Pakistan; muzaffar.ali@uettaxila.edu.pk (M.A.); \\ Tanzeel.ur.rashid@uettaxila.edu.pk (T.u.R.) \\ 2 Institute of Business Management, College of Engineering and Sciences, Karachi 7400, Pakistan; \\ rabia.hassan@iobm.edu.pk \\ * Correspondence: Muhammad.Mahboob14140@gmail.com \\ + Presented at the 1st International Conference on Energy, Power and Environment, Gujrat, Pakistan, \\ 11-12 November 2021.
}

\begin{abstract}
Energy forecasting and policy development needs a detailed evaluation of energy assets and long-term demand estimation. The demand forecast of electricity is an essential portion of energy management, particularly in the formation of electricity. It is necessary to predict electricity needs to avoid the energy deficits or a destabilization between energy demand and supply. In this article, long-range energy alternative planning (LEAP) is used for the modeling of energy and various sectors in Pakistan as a case study. The simulated model comprises three different scenarios, a strong economy, a weak economy, and a medium economy as a reference scenario. The base year is 2015 and the outlook year is 2040. Electricity demands are almost more than four times those of the outlook year, increasing from 7.71 million tons of oil equivalent (MTOE) in 2015 to 29.77 MTOE by the end of 2040 .
\end{abstract}

Keywords: leap; MTOE; forecasting; energy

check for

updates

Citation: Mahboob, M.; Ali, M.;

ur Rashid, T.; Hassan, R. Pakistan's Energy Demand Forecasting for Various Sector through Long Range Alternative Planning System. Eng. Proc. 2021, 12, 20. https://doi.org/ 10.3390/engproc2021012020

Academic Editor: Nazam Siddique

Published: 24 December 2021

Publisher's Note: MDPI stays neutral with regard to jurisdictional claims in published maps and institutional affiliations.

Copyright: (C) 2021 by the authors. Licensee MDPI, Basel, Switzerland. This article is an open access article distributed under the terms and conditions of the Creative Commons Attribution (CC BY) license (https:// creativecommons.org/licenses/by/ $4.0 /)$.

\section{Introduction}

Energy is considered the most important commodity of daily life. Energy utilization is an index of a country's economic situation because energy is an essential element of human activities and developments. There is a co-integrated relationship between population growth and energy consumption [1]. Every $1.07 \%$ increase in population growth rate can cause a $2.33 \%$ increase in total global energy consumption [2]. Population growth is not the only cause for an increasing energy demand, other factors like an increasing poverty level and an increase in the number of devices, appliances, level of comfort, and transportation [3-5]. Most energy is produced through fossil fuels; almost $84.7 \%$ of the total world energy consumption come from fossil fuels, in which $39.7 \%, 32.12 \%$, and $28.18 \%$ are the shares of oil, coal, and gas, respectively.

\section{Literature Review}

Energy challenges are crucial, but, at the same time, they are also complex and there are several parameters needed to assess the energy requirements and there are tremendous options to fulfill. A deep understanding of energy, environment, technology, and integrated policy planning is essential to address energy challenges. To estimate upcoming energy demands or emission values, statistical forecast techniques are used [6]. Neural networks not only help in prediction and estimation, they are also more efficient and accurate in optimum decisions, such as in the energy modeling of a building. As shown in Figure 1 a combination of energy, statistics, and computers have developed a new field in energy engineering known as "energy modeling". 


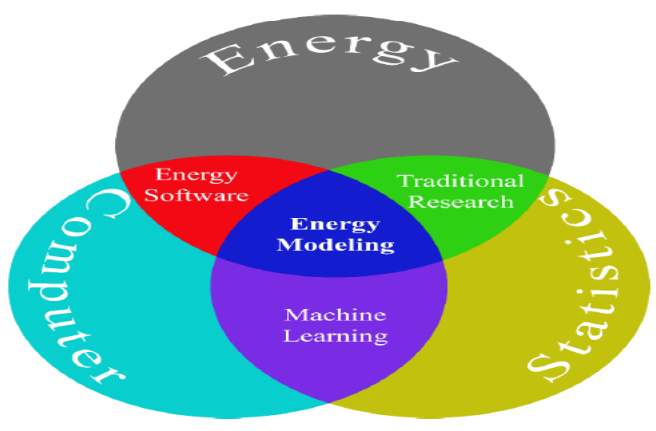

Figure 1. Merging disciplines in energy modeling.

\section{LEAP}

Long-range energy alternative planning system (LEAP) is a statistical energy modeling tool. LEAP was developed by the Stockholm Environment Institute in Boston, USA, and has been used since 1980 [7]. There are four modules in the LEAP program that are used to perform different types of modeling. They are key assumptions, demand, transformation, and resources [8]. The demand module consists of four sectors, household, industry, business, and public. In this article the main focus is on the forecasting of electricity demands in various sectors of Pakistan. In this model, results were based on three different scenarios: strong economy, base economy and weak economy scenarios. Each scenario depicts a separate storyline, based on policies considered for that scenario.

\section{Results and Discussions}

In the different scenarios, electricity demands were almost four times over those of the outlook year, increasing from 7.71 million tons of oil equivalent (MTOE) in 2015 to 29.77 MTOE by the end of 2040, as shown in Table 1. Residential electricity demands will be more than five times those of the forecast year in 2040, though the overall share of residential in electricity consumption will fall slightly from $54.36 \%$ in 2015 to $44.36 \%$ by 2040. In the commercial sector, the demand for electricity will be $11.88 \%$, slightly lower than $7.53 \%$.

Table 1. Electricity demand in all sectors.

\begin{tabular}{ccccccc}
\hline Sectors & $\mathbf{2 0 1 5}$ & $\mathbf{2 0 2 0}$ & $\mathbf{2 0 2 5}$ & $\mathbf{2 0 3 0}$ & $\mathbf{2 0 3 5}$ & $\mathbf{2 0 4 0}$ \\
\hline Agricultural & 0.9 & 1 & 1.2 & 1.3 & 1.5 & 1.7 \\
Commercial & 0.9 & 1.1 & 1.3 & 1.6 & 1.9 & 2.2 \\
Industrial & 1.7 & 2.6 & 3.8 & 5.7 & 8.4 & 12.5 \\
Residential & 4.2 & 5.3 & 6.6 & 8.3 & 10.5 & 13.2 \\
Transport & 0 & 0 & 0 & 0 & 0 & 0 \\
Total & 7.7 & 9.9 & 12.9 & 16.9 & 22.3 & 29.7 \\
\hline
\end{tabular}

The largest increases come from the industrial sector, as shown in Figure 2, which is responsible for $22.33 \%$ of the rise of electricity demand in 2015 to $42.18 \%$ in 2040 . The demand for electricity in 2015 by reference scenario increases from 1.72 MTOE and 12.55 MTOE in the outlook period, which is almost 7 times more than in the base year. In the strong economy scenario, demand increases almost 11 times more than the value of the base year. 


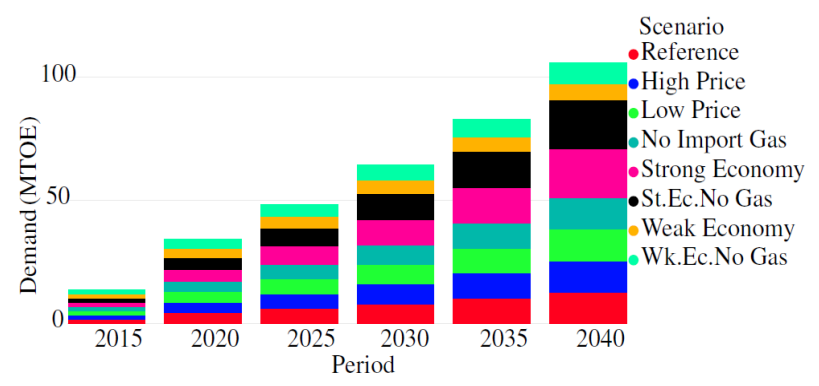

Figure 2. Electricity demand in industrial sector with different scenarios.

In commercial sectors, the demand for electricity was $11.88 \%$, which falls slightly to $7.53 \%$ over the outlook period. Figure 3 reveals that the total demand in 2015 for the reference scenario was $0.92 \mathrm{MTOE}$ and in 2040 it will be $2.24 \mathrm{MTOE}$, almost 2.5 times more than the base year of 2015 .

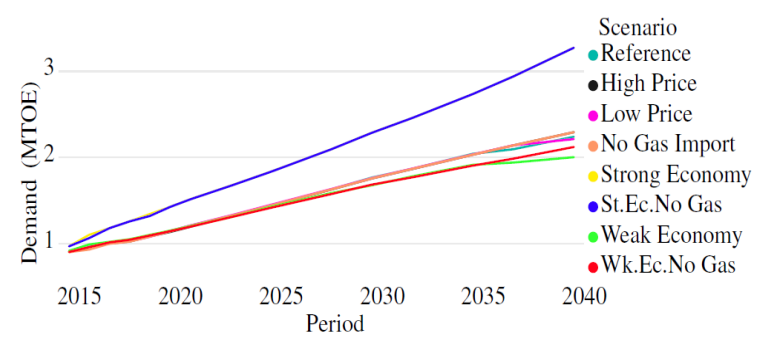

Figure 3. Electricity demand in commercial sector with different scenarios.

The residential sectors (urban and rural) shown in Figure 4 remain the largest consumers of electricity in Pakistan. The overall share of residential in electricity consumption falls slightly from $54.36 \%$ in 2015 to $44.36 \%$ by 2040 . The total demand in 2015 by the reference scenario was 4.19 MTOE and, in the outlook period, 2040 demand will be 13.2 MTOE.

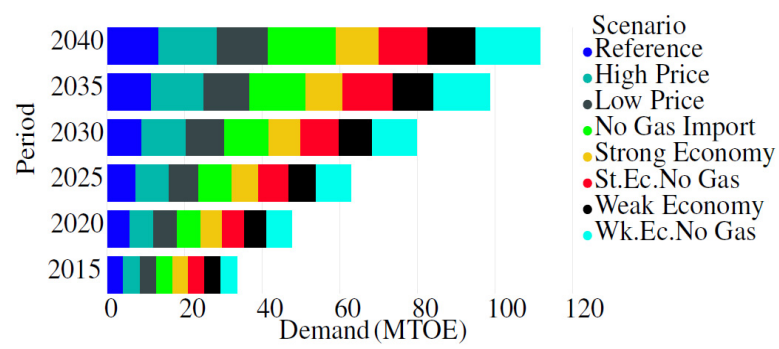

Figure 4. Electricity demand in residential sector with different scenarios.

Figure 5 indicates that electricity demand in the transport sector is very small as compared to other sectors; at less than $1 \%$ of the total in 2040, the demand of electric vehicles is much less in Pakistan over the outlook year. There is no need for electricity in the transport sector from the base year, 2015, through to 2020. After 2020, a sudden increase in electricity demands occurs when the prices of fuel will be high.

Electricity consumption by agricultural end users also falls from $11.42 \%$ in 2015 to $5.88 \%$ in 2040 . As Figure 6 indicates, the demand for electricity increases over the outlook year in the strong economy scenario. However, the overall impact on electricity consumption is decreased compared to the base year. 


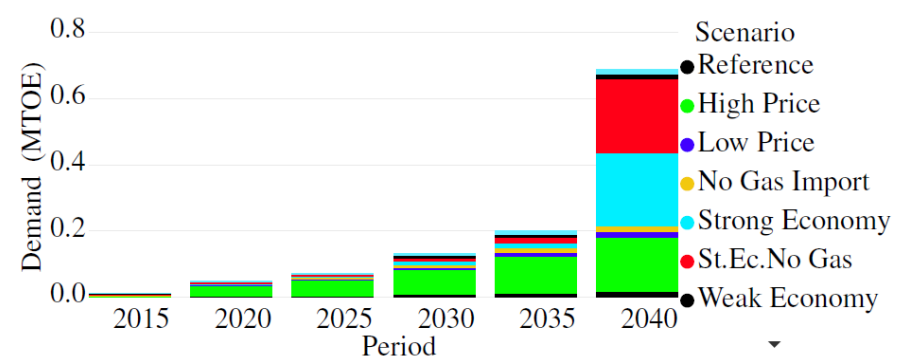

Figure 5. Electricity demand in transport sector with different scenarios.

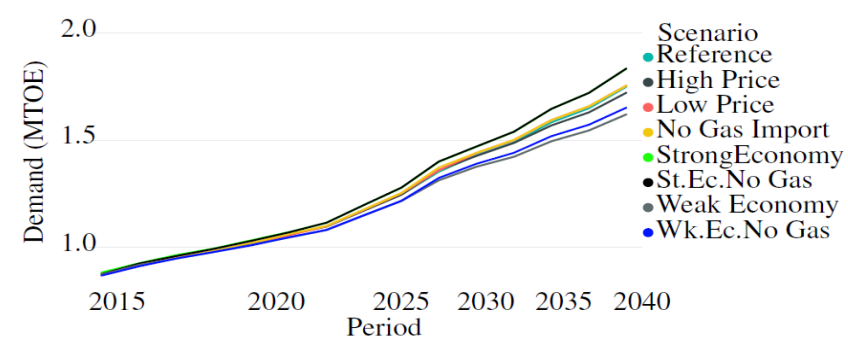

Figure 6. Electricity demand in agricultural sector with different scenarios.

\section{Conclusions}

In this study, the electricity demands of various sectors in Pakistan, from 2015 to 2040, are analyzed using LEAP. Different parameter, such as GDP, growth rate, and population, are included. Regression analyses are also used as governing equations for the forecasting of electricity over the outlook year. The forecast results and graphs indicate that the electricity demands increase every year, in almost all sectors. This ultimately indicates that the government and policy makers should make effective policies or take steps to meet the required demands for electricity. This article may help energy experts in Pakistan to find the best solutions to fulfill future energy demands.

\section{References}

1. Begum, R.A. $\mathrm{CO}_{2}$ emissions, energy consumption, economic and population growth in Malaysia. Renew. Sustain. Energy Rev. 2015, 41, 594-601. [CrossRef]

2. Jones, G.A. The 21st century population-energy-climate nexus. Energy Policy 2016, 93, 206-212. [CrossRef]

3. Nadimi, R. Energy use analysis in the presence of quality of life, poverty, health, and carbon dioxide emissions. Energy 2018, 96, 671-684. [CrossRef]

4. I. E. Agency. Digitalization and Energy; IEA: Paris, France, 2017.

5. I. E. Agency. Global EV Outlook 2018; IEA: Paris, France, 2018.

6. Bauer, N. Global fossil energy markets and climate change mitigation-An analysis with remind. Clim. Chang. 2016, 136, 69-82. [CrossRef]

7. T.O. Winarno. LEAP Energy Planning Guide; Center for Energy Policy Studies, Institut Teknologi Bandung: Bandung, Indonesia, 2006.

8. Perwez, U.; Sohail, A.; Hassan, S.F.; Zia, U. The Long-Term Forecast of Pakistan's Electricity Supply And 30 Demand: An Application of Long Range Energy Alternatives Planning. Energy 2015, 93, 2423-2435. [CrossRef] 